\title{
Influence of process parameters in electrostatic fluidized bed coating
}

\author{
M. Barletta*, V. Tagliaferri \\ Department of Mechanical Engineering, University of Rome "Tor Vergata", Via del Politecnico, 1-00133 Rome, Italy
}

Received 30 November 2004; accepted in revised form 6 April 2005

Available online 21 June 2005

\begin{abstract}
Experimental analysis of the electrostatic fluidized bed coating process of carbon steel thin sheets was performed using two different mesh-sized epoxy-polyester powders. In particular, systematic analysis of the influence of the operative variables on coating and process variability in the field of low film thickness (below $100 \mu \mathrm{m}$ ), was carried out, which for electrostatic fluidized beds has previously not been considered feasible.

In this context, the effect of varying both the electrostatic and fluidized bed setting on the amount of the powder layer coating the workpiece surface was studied. In particular, exposure time, applied corona voltage, and airflow rate were found to influence the performance of the coating process significantly.

Experimental results produced coating thickness trends consistent with theoretic expectations. In particular, effects on the coating process of both electric and aerodynamic forces, which in turn affect the powder particles drawn up to the work-piece surface could largely be predicted by examining experimental data. A set of 3D maps of the coating thickness achieved are also reported as they provide a useful tool to monitor the process in a 5-15 s time range, applied voltage from 45 to $90 \mathrm{kV}$, and flow rate from 3 to $11 \mathrm{~m}^{3} / \mathrm{h}$.
\end{abstract}

(C) 2005 Elsevier B.V. All rights reserved.

Keywords: Electrostatic fluidized bed; Coating process; Polymer powder; Electrostatic force; Aerodynamic force

\section{Introduction}

Growing concern for the environment nowadays and particularly the need to reduce amounts of volatile organic compound VOC emitted into the atmosphere are bringing about increasing use of powder coating as an alternative painting technology. This trend is driving the painting industry to meet new demands by re-arranging existing technologies. In this context, there is strong interest in any environmentally sustainable painting technology such as the electrostatic fluidized bed coating. Consequently, this paper thoroughly examines the coating of metal thin sheets using an electrostatic fluidized bed.

The electrostatic fluidized bed [1] coating process is based on a very simple principle. It employs a remote charging system to ionize dry air, which is forced out of a

\footnotetext{
* Corresponding author.

E-mail address: barletta@mail.mec.uniroma2.it (M. Barletta).
}

plenum chamber to pass through a porous plate into a reservoir of powder. The air suspends the powder, increasing its volume, and makes the powder act like a liquid. In addition, it charges each powder particle, creating a cloud of charged powder which actively seeks the previously grounded work-piece. This results in the charged particles being attracted and adhering to the work-piece.

Since the first few decades of the last century, several researchers have recognized the potential advantage of using electrostatic forces to improve deposition efficiency. Castle et al. traced the first electrostatic studies back to the 1930s [2]. In the 1940s, the first commercial versions of automated electrostatic paint lines were introduced and developed [2]. Meanwhile, during the 1950s a new solvent-free process was developed in Germany, based on the dipping of a heated surface in fluidized beds filled with thermoplastic powder [2]. From this a powder coating system based upon a fluidized bed began to evolve in which electrostatic coating played on an essential role. In spite of being a revolutionary method of painting, unlike electrostatic precipitation and 
electrostatic painting, not a single patent claimed this development. Nonetheless, only a few reports concerning electrostatic fluidized bed coating can be found in scientific literature. The first significant contributions were produced in the 1970s [3]. In 1994, Strucaly et al. accurately related how the supplier of fractional horsepower motors for automotive uses had taken advantage of this technology since the 1970s. After this, Strucaly proposed an innovative use of a proven technology to solve all the manufacturing problems of painting wires [4]. No other relevant experimental analysis is to be found in the literature and, at the time of writing, a systematic experimental approach to electrostatic fluidized bed coating process is still lacking.

Meanwhile, several papers described and numerically simulated the electrostatic powder coating process. Ali et al. [5] were the first to attempt a simulation of the coating process in an electrostatic fluidized bed. In a further work [6], they also studied the effects of the ratio between the fluidized bed and work-piece size in the coating process. Moreover, several models simulating electrostatic spray painting based on Lagrange's approach were proposed $[7,8]$. Simulations were rarely successfully supported by corresponding experimental investigation leaving more than a little uncertainty concerning the reliability of the models developed.

Lastly, very few significant contributions can be found in the literature because powder coaters have had little interest in this technology. This has been caused by several alleged drawbacks such as the large volume of powder required to load the system, the lack of flexibility in coating workpieces with complex shapes, the problems with color change, and above all, the erroneous idea that only films thicker than $250 \mu \mathrm{m}$ can be applied.

Therefore, the aim of this work is, firstly, to examine the influence of all the process parameters and of fluidized bed hydrodynamic on coating thickness trends in the field of most interest to industry (below $100 \mu \mathrm{m}$ ). Secondly, to demonstrate the ability to control the process in operative ranges, and at the same time, to provide useful data collection to calibrate new and more reliable numerical simulations. Therefore, in order to increase the accuracy of experimental data collected, both thermo-reological and physical properties of tested thermoset powders were accurately measured, and in addition, a full statistical approach in all phases of experimental investigation was employed. Finally, experimental trends were explained by taking the role of both the aerodynamic and electrostatic forces into consideration.

The comparative analysis of investigated parameters demonstrates that the results obtained were consistent with theoretic expectations, the trends of coating thickness being consistent with powder characteristics, electric parameters, and hydrodynamic behavior of the bed. On this basis, useful process maps were built and the most convenient process windows were identified. As a direct consequence, these experimental results also provide the basis for the develop- ment of a numeric model unaffected by unreliable experimental calibration. At the same time, an analytical model based on both mathematical and physical considerations was developed and validated which provides the first ever reliable forecasts for electrostatic fluidized bed coating process.

\section{Experimental apparatus and procedure}

\subsection{Fluidized bed coating and apparatus}

The electrostatic fluidized bed powder coating process utilizes a remote charging media to ionize dry air which is forced to pass from a plenum chamber through a porous plate into a reservoir of powder, having been fed through a fluidization column beforehand (Fig. 1).

As soon as the powder particles become charged, they repel each other, and rise from the base of the fluidizing bed chamber causing a cloud of ionized powder. When a grounded work-piece is dipped in the cloud, the charged particles are attracted to the substrate, temporarily adhering to it before the curing process.

The fluidization system consisted of a circular grounded column $250 \mathrm{~mm}$ in diameter and $500 \mathrm{~mm}$ in height. The electrically grounded column was made from metal with a thickness of $5 \mathrm{~mm}$ to provide wall rigidity and resistance to wear. Plexiglas windows were used to have a check on the process. A set of charging electrodes, fed by a high voltage supply (dc $0-100 \mathrm{kV})$ with a negative polarity on electrodes, was placed inside the bottom part of the bed so that the powder material would be charged as the fluidizing air caused it to rise up (Fig. 1-b).

There is an inlet section at the base of the column, which is often called the homogenization section, which is designed to produce a uniform air flux throughout the whole cross-section of the tubular reactor. Such a uniform air flux avoids deviations from ideal hydrodynamic behaviors in the fluidized bed, for the purpose of which the homogenization section was filled with ceramic material (Rashig's rings). The air distributor, composed of a $20 \mathrm{~mm}$ thick polymeric porous plate, was located in the bottom part of the fluidization column to support powders when they were not fluidized and, at the same time, to assure the passage of the fluidization air. The air distributor was designed so as not to modify the velocity distribution produced by the homogenizing section.

\subsection{Materials and preparation of specimens}

\subsubsection{Materials}

Two types of hybrid epoxy-polyester powders, respectively characterized by two different grit size distributions (Fig. 2), with a dielectric constant of about 3 and a surface resistivity around $10^{11}-10^{12} \Omega$ /square were employed as raw material. Both powders were supplied as finely divided 
a

(1)

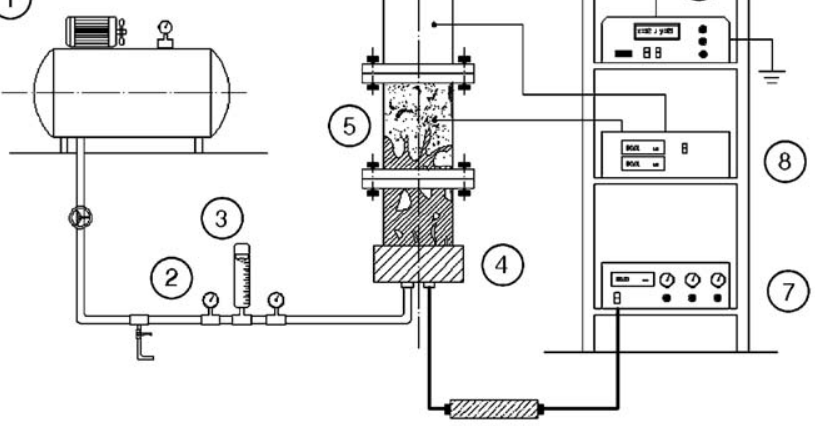

(6)
(1) Air

compressor

(2) Manometer

(3) Flow rate meter

(4) Distributor with filter

(5) Fluidized bed

(6) Transformer

(7) Voltage controller

(8) Data acquisition unit

(9) Movement system

(10) Specimen

\section{b}

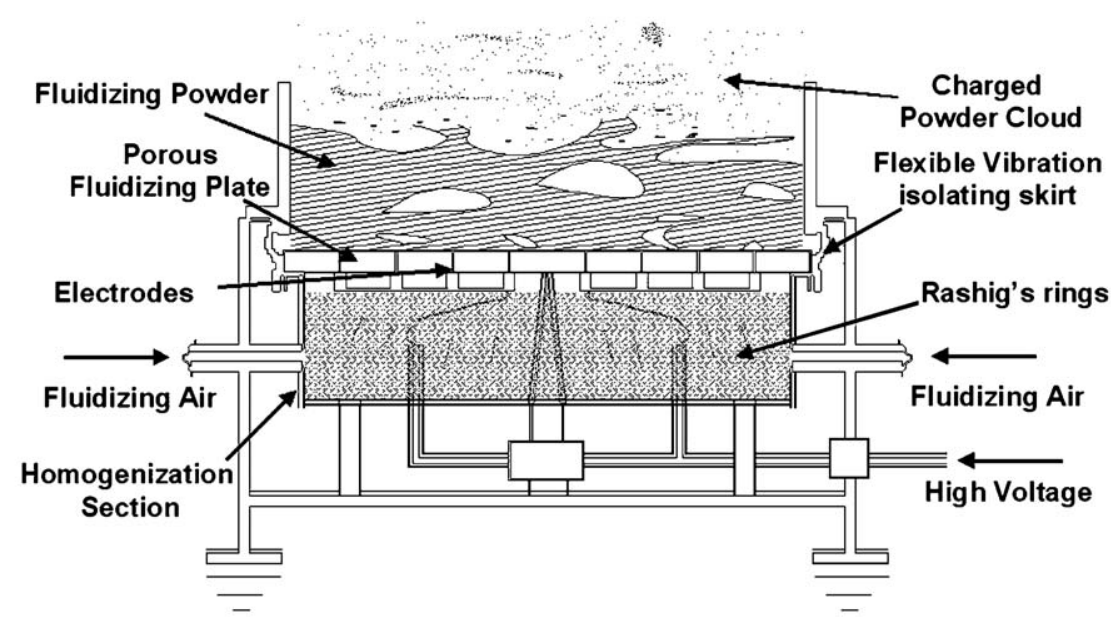

Fig. 1. a: Plant scheme, b: Spot on fluidization column.

powder. The size distribution of the two powders chosen was obtained by using the Laser Sympatec Granulometer. The finer powder had a distribution peak set at $25 \mathrm{~mm}$ with $90 \%$

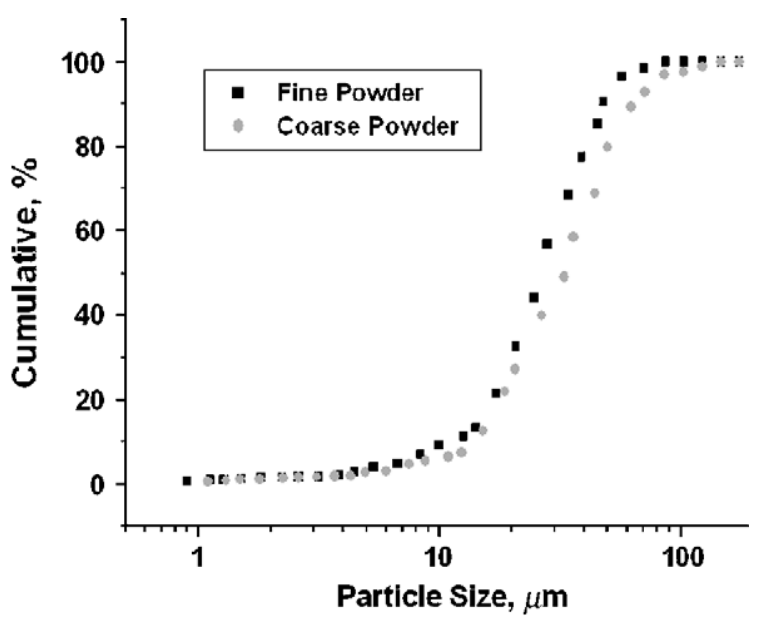

Fig. 2. Grain size distribution of hybrid powders. of distribution below $55 \mathrm{~mm}$. The coarser powder had a mean diameter of $35 \mathrm{~mm}$ and $90 \%$ of distribution below 75 $\mathrm{mm}$. Geldart's map refers to both powders as 'C group' [1].

Thermal properties of the coating were accurately characterized in order to understand what exactly the powder aptitude to coating operation was. Fig. 3 shows the DSC signal resulting from temperature variations from 25 to $250{ }^{\circ} \mathrm{C}$. The exothermic crosslinking reaction occurred during the first heating. No additional curing reaction was noted during second heating. The glass transition temperature of cured resin was $73.3{ }^{\circ} \mathrm{C}$, the heat of reaction was found to be $41.3 \mathrm{~J} / \mathrm{g}$. The powders experienced a strong relaxation enthalpy during first heating which was probably caused by the production process. Annealing at the corresponding peak temperature produced a complete disappearance of relaxation enthalpy during the following heating.

The properties of the two different particle sized powders are summarized in Table 1 and compared with other commercially available powders. 


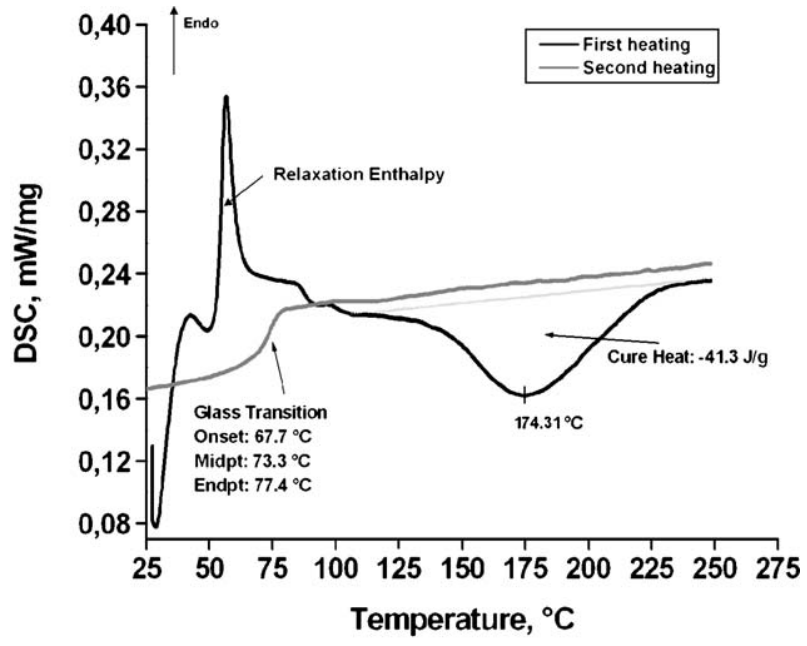

Fig. 3. DSC signal for hybrid powders.

Work-pieces coated during experimental tests were thin sheets ( $1 \mathrm{~mm}$ thick, $50 \mathrm{~mm}$ in width, and $100 \mathrm{~mm}$ in height) of low carbon steel with low resistivity (nearly $10 \mu \Omega \mathrm{cm}$ ). Before coating, the specimens were polished by abrasive blast cleaning, followed by phosphoric acid cleaning, and then a water rinse, a chromic acid rinse, and a forced-air rinse before being exposed to a set of prepaint treatments [9].

\subsubsection{Hydrodynamic behavior of the powders}

The polymeric powders were sieved into dominant size ranges using standard sieves so that all contaminants and clusters were eliminated from them. After this, the powders were fed to the bed and accurately dried by fluidizing a low flux of dry and clean air. Next, the airflow to the bed was increased to a high value and the powder in the bed was allowed to mix thoroughly for a few minutes.

When fed with the finer powder, the fluidized bed had a minimum fluidization flow of $0.65 \mathrm{~m}^{3} / \mathrm{h}$ corresponding to a minimum fluidization velocity of $0.0032 \mathrm{~m} / \mathrm{s}$. A slight difference was experienced when fluidizing the other powder. For both powders bubbling regime was maintained within an airflow range of $3.5-7 \mathrm{~m}^{3} / \mathrm{h}$ corresponding to
Table 2

Reduced experimental plan (25 tests, replicated three times)

\begin{tabular}{llll}
\hline Levels & Factors & & \\
\cline { 2 - 4 } & Exposure time $(\mathrm{s})$ & Airflow $\left(\mathrm{m}^{3} / \mathrm{h}\right)$ & Applied voltage $(\mathrm{kV})$ \\
\hline I & 5 & 3 & 50 \\
II & 8 & 5 & 60 \\
III & 10 & 7 & 70 \\
IV & 12 & 9 & 80 \\
V & 15 & 11 & 90 \\
\hline
\end{tabular}

superficial velocities 5-10 times the minimum fluidization velocity. Bubbling regime was still on at a flow rate of 10 $\mathrm{m}^{3} / \mathrm{h}$, but powder spouts started to rise from dense phase of the bed to the free board.

\subsection{Experimental procedure and plans}

After pre-treatments, surface preparations and dimensional controls performed by using a Mitutoyo Digital Palmer $( \pm 1 \mathrm{~mm}$ as accuracy), workpieces were grounded. They were then dipped in the free board zone [1] of the electrostatic fluidized bed (i.e. the zone immediately above the powder dense phase [1]) by using a pneumatic movement system. The apparatus and coating procedure was accurately described in a previous paper [10]. In this context, it is important to note that work-pieces were generally placed at a distance of $100 \mathrm{~mm}$ away from the bed dense phase, whose height was kept fixed in minimum fluidization at $230 \mathrm{~mm}$. The environmental conditions were always kept under firm control in order to avoid systematic error affecting the experimental data. Consequently, all the experiments were carried out at a relative humidity of less than $40 \%$ with an average temperature of $20{ }^{\circ} \mathrm{C}$ (accuracy $\pm 0.2{ }^{\circ} \mathrm{C}$ ). Once the exposure time elapsed, the holder was removed from the column. Next, the specimen was picked up from the holder and positioned in the oven and cured at $170{ }^{\circ} \mathrm{C}$ for $11 \mathrm{~min}$ to establish the full film properties the material was designed for. After the cure, the specimens were examined by monitoring the amount of deposited polymer using a coating thickness gauge based on magnetic field, and a Mitutoyo Digital Palmer was also used to perform a further check. The

Table 1

Material properties

\begin{tabular}{lllllll}
\hline Property & \multicolumn{2}{l}{ Properties of thermosetting powder coatings } & & \\
\cline { 2 - 6 } & Epoxy & Polyurethane & Acrylic & Polyester & Hybrid fine & Hybrid coarse \\
\hline Weatherability & Poor & Good & Excellent & Excellent & Fair-Poor & Poor \\
Corrosion resistance & Excellent & Very good & Good & Very good & Excellent-Very good & Very good \\
Chemical resistance & Excellent & Very good & Very good & Very good-Good & Very good & Good \\
Heat resistance & Very good & Very good & Good & Good & Very good-Good & Very good-Good \\
Impact resistance & Excellent & Very good & Good-Fair & Good & Very good & Very good \\
Hardness & HB-5H & HB-3H & HB-4H & HB-4H & HB-3H & HB-3H \\
Flexibility & Excellent & Very good & Good-Fair & Very good & Very good & Very good \\
Adhesion & Excellent & Very good & Good-Fair & Excellent & Excellent & Excellent \\
\hline
\end{tabular}


Table 3

Full factorial experimental plan (50 tests, replicated four times)

\begin{tabular}{llll}
\hline Levels & \multicolumn{2}{l}{ Three factors } & \\
\cline { 2 - 4 } & Exposure time $(\mathrm{s})$ & Airflow $\left(\mathrm{m}^{3} / \mathrm{h}\right)$ & Applied voltage $(\mathrm{kV})$ \\
\hline I & 7 & 3 & 50 \\
II & 14 & 5 & 60 \\
III & & 7 & 70 \\
IV & & 9 & 80 \\
V & & 11 & 90 \\
\hline
\end{tabular}

thickness was evaluated by performing nine measurements equally spaced along the surface of each work-piece. The coating thickness was taken as the average of all the measurements.

Several sets of experimental tests were performed. First, a fractional factorial design (Taguchi design) was developed to investigate the relative influence of exposure time, applied voltage and airflow using the two different powders (Table 2). The levels were set on the basis of results obtained from several preliminary tests. A general linear model ANOVA was employed to discuss the importance of each process parameter and to bring out the eventual difference between the two powders. As shown in Table 3, the next step was a full factorial experimental plan, employing three factors and replicated four times, involving just one powder. These were carried out to establish the process leading mechanisms, to examine the combined effect on coating process of each of the operative variables, and lastly, to identify the best operative process conditions. Finally, Table 4 reports verification experimental plan (full factorial on two factors), which was performed in order to check process reproduceability and reliability by setting the electric parameters (applied voltage) at the level $(70 \mathrm{kV})$ found to be the best for the coating. A total of 355 experimental tests were carried out. A strict statistical approach was followed in examining and reporting experimental data.

All experimental results are reported as means with standard deviations. Reliability and reproduceability of results were checked using a general linear model ANOVA and analysis of residuals. Advanced regression models were used to find the best fit for the experimental results, and to interpret them.

Table 4

Verification experimental plan (20 tests, replicated four times)

\begin{tabular}{lll}
\hline Levels & Two factors & \\
\cline { 2 - 3 } & Exposure time $(\mathrm{s})$ & Airflow $\left(\mathrm{m}^{3} / \mathrm{h}\right)$ \\
\hline I & 4 & 3 \\
II & 7 & 5 \\
III & 11 & 7 \\
IV & 14 & 9 \\
V & & 11 \\
\hline
\end{tabular}

\section{Experimental results and discussion}

3.1. Identification of leading process parameters and the influence of powder size: an initial experimental-statistical approach

A thorough examination of the significance of operative parameters and powder size on the coating process was carried out. Fig. 4 reports the analysis of means for the two powders used in relation to coating thickness in response to variations in the exposure time, the applied voltage, and the airflow. A closer examination of experimental data shows the strong influence of both the applied voltage and airflow on coating thickness. Furthermore, the slight influence of exposure time can be seen. Table 4 reports the numerical results of applying a general linear model ANOVA to this experimental data. Comparing estimated Fisher's values with those tabulated shows that each investigated factor in the coating process cannot be disregarded, even if the difference in contribution percentage $\Pi(\%)$ (i.e. $S S_{\mathrm{k}} / S S_{\mathrm{t}}$ ) of each factor determines a major influence of airflow and applied voltage in agreement with the results from the analysis of means. In conclusion, slight variations in the level of airflow or applied voltage can also cause relevant modifications in coating thickness. In contrast, to produce visible alterations in coating thickness, a large difference in exposure time levels is essential.

The interpretation in terms of the physics can be reasoned as follows: as is well known, the electrostatic deposition process is managed by a force system. Aerodynamic and electrical forces can be considered as positive forces in the deposition process because they respectively cause the powders to travel towards the grounded target and to adhere to it firmly. On the contrary, both the air resistance and gravity act directly in opposition with the two positive forces resulting in less powder to deposit on substrate. Therefore, an increase in both the applied voltage and

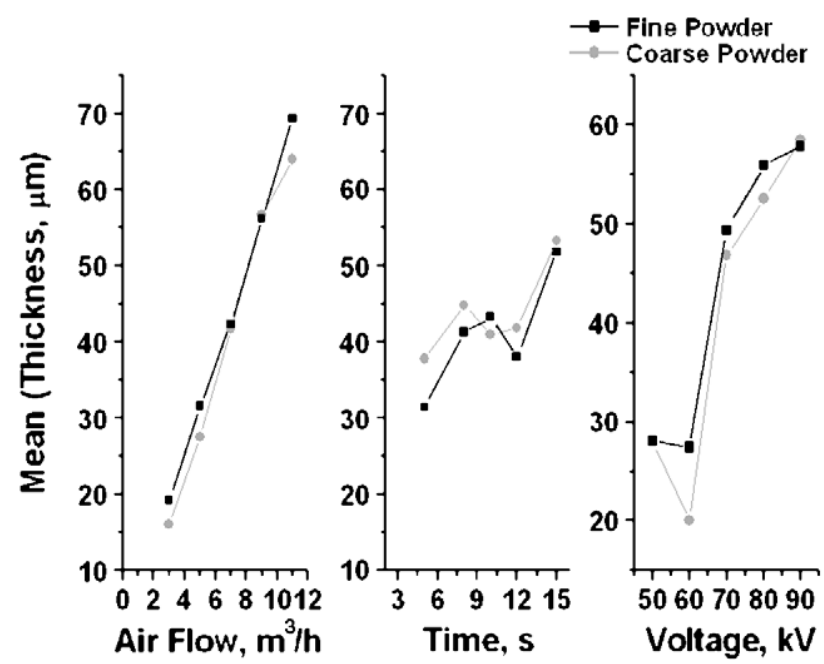

Fig. 4. Analysis of mean in Taguchi experimental plan using both powders. 
airflow causes a rise in the two positive forces keeping the other forces in the process constant. Thus slight variations in these two operative parameters produce more favorable conditions for coating process and so larger coating thickness can be deposited easily. At the same time, a growth in airflow produces a massive powder elutriation phenomenon from the dense phase of fluidized bed towards the free board zone where the deposition process takes place. Therefore, more powder is in close proximity and so can adhere to the grounded substrate, thus determining faster growth of the powder layer. In this context, the exposure time seems to have little influence because it does not directly act on a force active in the process but only on the duration of it. So if all the other operative parameters are kept constant, for exposure time to have any bearing on the coating thickness and on the whole deposition process, a very large difference in exposure time must be applied (i.e. from $5-15 \mathrm{~s}$ ).

Nevertheless, from glancing at the error contribution percentage $\Pi(\%)$ (i.e. $S S_{\mathrm{w}} / S S_{\mathrm{t}}$ ) in Table 5, set at about $20 \%$, it is clear that all the experimental and statistical considerations previously outlined above are still affected by a high margin of uncertainty.

Furthermore, the results in Fig. 4 reveal a slight difference between the two investigated powder typologies. In fact, the experimental data prove to be a good match between coating thickness attained for both the powders used. Nevertheless, even if examination of the coating thickness provides no direct confirmation, the physical behavior of the two different sized powders is clearly different in terms of powder transportation (different minimum fluidization speed), electrostatic charging of powder particles (different $\mathrm{q}(\mathrm{t})$ in accordance with the specifications of Pauthenier's law [11] which correlates charge on single particle according to the radius $r^{2}$ of the particle itself) and window paning effect (different coating thickness around the edge or work-piece recess), formation of a not uniform powder cloud in the surrounding air (different stratification of the powder in the free board zone), powder deposition and build up rate on the substrate (difference in powder packing onto grounded substrate), and lastly, transfer efficiency (different powder density and transit time in free board zone).

Table 6 summarizes the differences between the coating quality and performance of the powders examined through the use of intermediate levels of voltage $(70 \mathrm{kV})$, airflow (7

Table 5

ANOVA table for Taguchi experimental plan

\begin{tabular}{lrrlrl}
\hline Factors & \multicolumn{3}{l}{ Indexes } & & \\
\cline { 2 - 6 } & $d f$ & \multicolumn{1}{l}{ SS } & MS & \multicolumn{1}{l}{$F$} & $\Pi$ \\
\hline Applied voltage $(\mathrm{kV})$ & 4 & $16,218.94$ & 4054.73 & 15.12 & $26.75 \%$ \\
Airflow $\left(\mathrm{m}^{3} / \mathrm{h}\right)$ & 4 & $23,643.18$ & 5910.80 & 22.04 & $39.20 \%$ \\
Exposure time (s) & 4 & 9333.92 & 2333.48 & 8.70 & $14 \%$ \\
Residual & 62 & $17,434.72$ & 268.226 & & $20.05 \%$ \\
Total & 74 & $66,630.76$ & & & \\
\hline
\end{tabular}

Table 6

Comparison between coating using finer and coarser powders

\begin{tabular}{lll}
\hline Surface status & Coating material & \\
\cline { 2 - 3 } & Finer powder & Coarser powder \\
\hline Shrinkage & Minimized & Minimized \\
Voids & Minimized & Present \\
Pin holes & Minimized & Relevant \\
Orange peels & Minimized & Relevant \\
Edge cover & Minimized & Maximized \\
\hline
\end{tabular}

$\left.\mathrm{m}^{3} / \mathrm{h}\right)$ and exposure time $(10 \mathrm{~s})$ as the operative parameters. Fig. 5 reports surface defects produced when using the coarser powder. Particle size determines the quality of coating to a great extent, even if it does not influence its thickness. In fact, it affects the tendency of the powder to be free flowing. This fluidity not only depends on the powder material but also on the shape and the size of particles as these determine powder packing on the grounded substrate. However, when larger particles are deposited, the voids in the coating are greater, increasing the difficulty in achieving a thin uniform coating, unless the polymer has exceptionally good flow out. At the same time, even if it is generally easier to obtain a smoother coating film with smaller particles, unfortunately due to the poor fluidity, it is extremely difficulty to apply them. Therefore, in terms of appearance and performance on substrate, although the powder chosen does not seem to influence the coating thickness, the type and grade of raw materials selected for the powder coating material, how they are used in the formulation, together with the powder particle shape, size and distribution, all significantly affect the quality of the coating.

\subsection{The analysis of leading process parameters: effects of exposure time, voltage and flow rate on coating thickness}

Analysis of coating process was based on film thickness trend, determined by observing variations in the operative parameters. On the basis of cues provided by experimental data from the Taguchi design, a full factorial experimental plan was scheduled. Since they are the most influential factors, both the applied voltage and the airflow were set at five distinct levels, with the exposure time only being set at two distinct levels as it is less important as a factor affecting coating thickness. With regard to this, just the finer powder was examined because it exhibited the best overall behaviour during the previous tests and no relevant discrepancy in coating thickness occurred when the two powder typologies were examined.

The experimental data (Figs. 6 and 7) clearly demonstrate the fluidized bed can apply films less than $100 \mu \mathrm{m}$ thick, and manage the process accurately. In particular, Figs. 6 and 7 are 3D maps of coating thickness produced by varying the applied voltage at several airflow levels after exposure times of 7 and 14 s. Figs. 8 and 9 show the related average roughness trends obtained. 


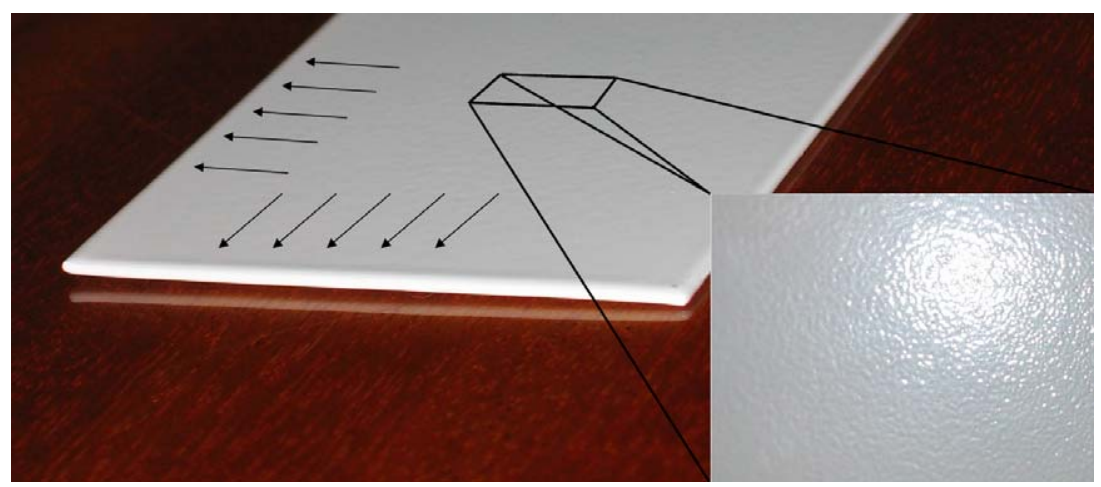

Fig. 5. Surface coating appearance (window paning and 'orange peel' effect).

A similar trend seems to characterize the coating thickness for both the exposure times (7 and $14 \mathrm{~s}$ ) and all applied voltages. Of relevance, an initial rise in coating thickness is obtained from increasing the applied voltage. Then, after a maximum value has been achieved, a strong decrease in thickness clearly occurs. This trend is common to all the investigated airflow levels, even if a top shift of curve is clearly evident.

Once again, physics can interpret this phenomenon in terms of a force system acting in the vicinity of and around grounded targets. As previously stated, when moving through the electric field established in fluidized bed, powder particles are affected by aerodynamic, electric, gravity, and frictional forces. Nevertheless, during the coating process, there are only two forces playing a fundamental role in determining coating thickness trends. Firstly, the aerodynamic, which are very active all over the fluidized bed, and secondly, electrical forces, whose influence is very strong, very close to the grounded substrate. The former exclusively depends on the superficial speed, and as the latter are a function of the applied voltage, they can be controlled accurately.

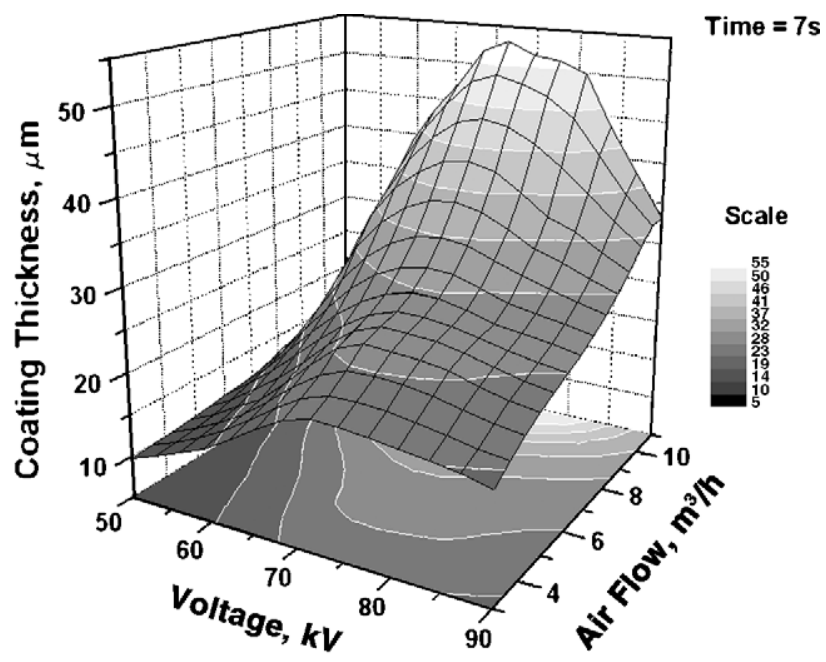

Fig. 6. Coating thickness produced by varying applied voltage in the parameter flow rate ( $7 \mathrm{~s}$ as exposure time).
Since the ratio between the two forces can be made to vary widely by carrying out the experimental tests at constant superficial velocity and varying the value of applied corona voltage within the operative range (50 and $90 \mathrm{kV}$ ), electric force can be isolated from the influence of aerodynamic force and so interpreted independently.

The increase in applied voltage produces discernible effects on coating thickness. A closer examination reveals that when the exposure time remains fixed, the initial fast increase in coating thickness with increase in the voltage level is determined by the growth of electrical force. This initial effect can be easily understood if the electric field established between the electrode and the grounded target is considered. Increasing the charge on the corona wire intensifies the electric field, that is, stepping up the applied voltage. Since the electrostatic force $F_{\mathrm{E}}=q(t) E$ involved in deposition process is a growing function of charge on powder $q(t)$, as soon as the applied voltage steps up, $q(t)$ soars, and the electric force consequently increases. As a result, the powder covers the grounded substrate with a thicker film. Nevertheless, when the applied voltage rises over a threshold (over $70 \mathrm{kV}$ ), rapid ionization of air trapped

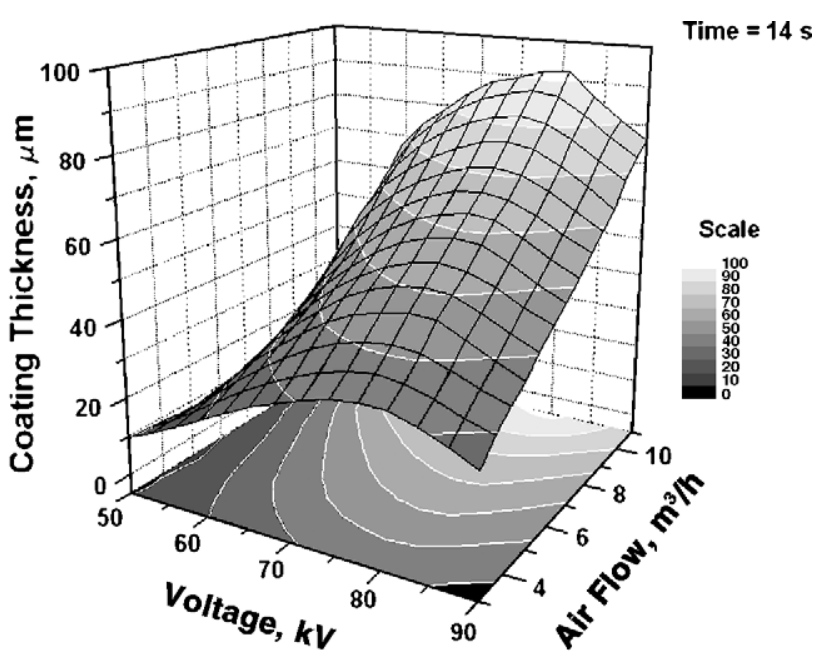

Fig. 7. Coating thickness produced by varying applied voltage in the parameter flow rate (14 $\mathrm{s}$ as exposure time). 


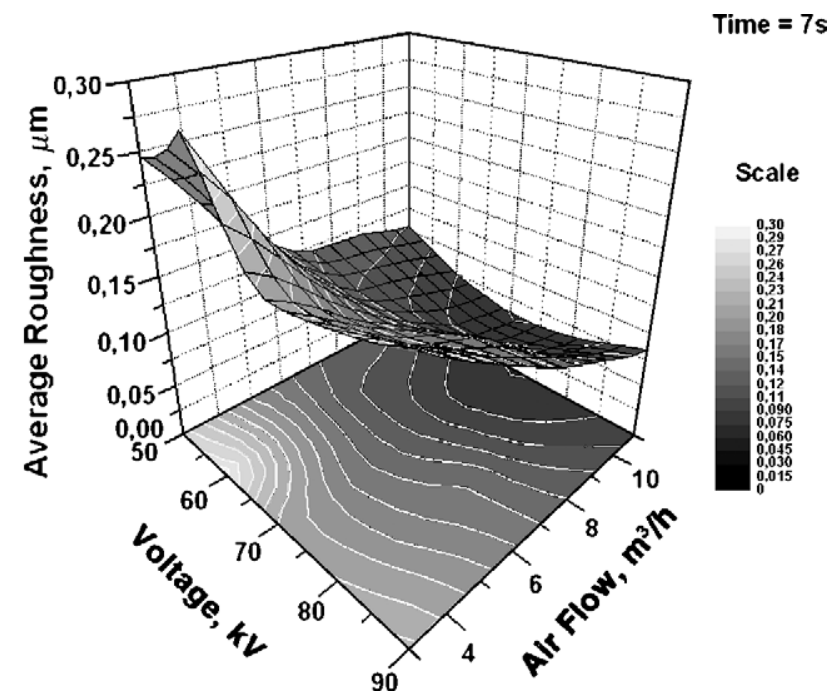

Fig. 8. 3D map of the average roughness produced by varying applied voltage and flow rate ( $7 \mathrm{~s}$ as exposure time).

in the powder layer already adhered onto grounded target occurs because the substrate surfaces are strongly and rapidly polarized. This causes the onset of an ion flux to and from the coated surface (namely, streamers [11]) which causes a reduction of coating thickness by detaching the not well-adhered powder layer and by preventing further powder from being deposited onto the substrate (saturation phenomenon). At the same time, surface finishing deteriorates (back ionization) due to the streamers, which pierce the whole deposited layer with craters.

However, an increase in airflow always independently produces relevant growth in coating thickness whatever the setting of applied voltage. As previously mentioned, airflow only acts on aerodynamic force. Incidentally, a growth in airflow produces a larger amount of elutriated from the dense phase. At the same time, the coarse zone (TDH(C) [1]) and the fine zone $(\mathrm{TDH}(\mathrm{F})[1])$ in the free board zone move towards the top of the column, modifying the density of the bed at different heights. In particular, if the vertical location of grounded substrate in the bed is kept constant, more powder and of a larger size is made available for attraction to the work-pieces, and adhere to them. Therefore, since electrostatic force is most active near the grounded substrate, thicker layers can be expected in such situations. In fact, the data collected in Figs. 6 and 7 show that a growth in airflow causes an immediate top shift of coating thickness trend so experimental data match theoretical expectations very well. Moreover, an increase in powder density close to the grounded substrate causes back ionization phenomena to speed up with a consequent faster decrease in coating thickness at higher voltage levels.

In addition, the influence of particle exposure time in relation to the electric field was investigated. At a higher exposure time, the powder particles reach a corresponding higher charge to mass ratio, which is related to the applied corona voltage in each case. Examination of the experimental data clearly shows growth in the thickness trend when the exposure time between the two investigated levels is varied. However, at the lowest level of exposure time (7 s), even if the coating thickness already suffers the effects of electrostatic force, fewer electric phenomena occur compared with those affecting the deposition process after $14 \mathrm{~s}$ as exposure time.

The 3D maps reported in Figs. 8 and 9 reveal the complete trend in average roughness obtained by varying both the applied voltage and the airflow. Three map segments can be identified: a first zone, typical of low airflow values (less than $7 \mathrm{~m}^{3} / \mathrm{h}$ ), in which the low coating thickness determine a poor surface finishing whichever the voltage applied. A sort of incubation value of airflow can be defined below which nothing happens in terms of the influence of charge to mass ratio on average roughness. In each case, the thickness of the polymer layer was very thin indeed for practical purposes (less than $40 \mu \mathrm{m}$ ). A second zone is formed where the applied voltage is lower than 70 $\mathrm{kV}$ but the airflow is faster than $7 \mathrm{~m}^{3} / \mathrm{h}$. Here faint variations in airflow determine relevant modifications (ranging from $30 \%$ to $80 \%$ ) on attained average roughness. No back ionization phenomenon seems to occur below $70 \mathrm{kV}$. In fact, as previously seen in Fig. 7 , increasing the exposure time causes a further growth in coating thickness without any deterioration of surface finishing (Fig. 9). Finally, a third zone can be identified for higher applied voltages: strong back ionization phenomena seem to characterize this map segment. In fact, the merest slight variation of applied voltage is enough to introduce a significant increase in average roughness associated with a decreasing of coating thickness (as seen in Figs. 6 and 7) and consequent deterioration of surface finish with the occurrence of diffuse grooves, pin holes, voids, and the 'orange peel' effect.

Table 7-a and -b, and Fig. 10, respectively report the ANOVA table and the analysis of mean for the full factorial

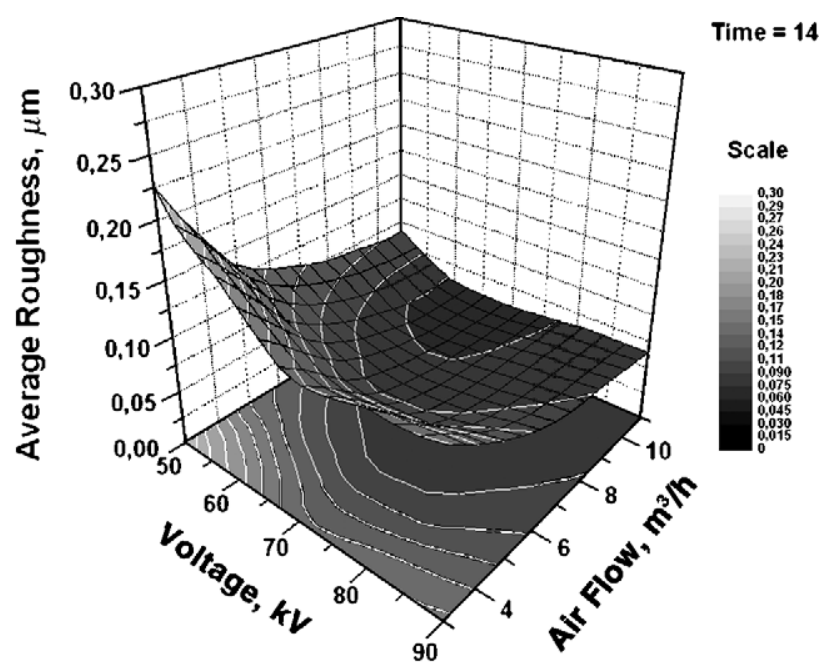

Fig. 9. 3D map of the average roughness produced by varying applied voltage and flow rate (14 $\mathrm{s}$ as exposure time). 
Table 7

a: Results of ANOVA table on full factorial experimental investigation by considering interactions between investigated factors

\begin{tabular}{|c|c|c|c|c|c|}
\hline \multirow{2}{*}{$\begin{array}{l}\text { Interactions } \\
\text { Factors }\end{array}$} & \multicolumn{5}{|c|}{ Source } \\
\hline & $d f$ & Seq SS & Adj MS & $F$ & $\Pi(\%)$ \\
\hline Time & 1 & $13,945.6$ & $13,945.6$ & 1233.46 & 18.96 \\
\hline Voltage & 4 & $24,074.8$ & 6018.7 & 532.3 & 32.73 \\
\hline Airflow & 4 & $23,543.8$ & 5886 & 520.6 & 32.01 \\
\hline Time* Voltage & 4 & 4205.2 & 1051.3 & 92.98 & 5.71 \\
\hline Time* Airflow & 4 & 2308.3 & 577.1 & 51.04 & 3.13 \\
\hline Voltage * Airflow & 16 & 3837 & 239.8 & 21.21 & 5.21 \\
\hline $\begin{array}{l}\text { Time } * \text { Voltage* } \\
\text { Airflow }\end{array}$ & 16 & 502.8 & 31.4 & 2.78 & 0.68 \\
\hline Error & 100 & 1130.6 & 11.3 & & 1.53 \\
\hline Total & 149 & $73,548.1$ & & & \\
\hline
\end{tabular}

b: Results of ANOVA table on full factorial experimental investigation by not considering interactions between investigated factors

\begin{tabular}{|c|c|c|c|c|c|}
\hline \multirow{2}{*}{$\begin{array}{l}\text { No interactions } \\
\text { Factors }\end{array}$} & \multicolumn{5}{|c|}{ Source } \\
\hline & $d f$ & Seq SS & Adj MS & $F$ & П(\%) \\
\hline $\begin{array}{l}\text { Applied } \\
\text { Voltage }(\mathrm{kV})\end{array}$ & 4 & $24,074.8$ & 6018.61 & 70.31 & 32.73 \\
\hline Airflow $\left(\mathrm{m}^{3} / \mathrm{h}\right)$ & 4 & $23,543.8$ & 5886.0 & 68.76 & 32.01 \\
\hline $\begin{array}{l}\text { Exposure } \\
\text { time (s) }\end{array}$ & 1 & $13,945.6$ & $13,945.6$ & 162.92 & 18.96 \\
\hline Residual & 140 & $11,983.9$ & 85.6 & & 16.29 \\
\hline Total & 149 & $73,548.1$ & & & \\
\hline
\end{tabular}

experimental investigation. Examination of the data collected reveals the significance of both the applied voltage and airflow, in agreement with previous observations. By disregarding all the interactions, a contribution percentage $\Pi(\%)$ for residuals, set at about $15 \%$ with a $M S_{\mathrm{w}}$ of 85.6 (Table 7-b), confirms the significantly improved reliability of experimental plan compared with the Taguchi design, even though less $d f$ are engaged in full factorial design (over 9 against $16 d f$ ). The reduction in film thickness due to the strong effect of back ionization phenomenon can be readily seen in the trends shown in Fig. 10.

Figs. 11 and 12 report the analysis of residuals performed on full factorial experimental design. Probability plot, normality test (Shapiro-Wilk), and residuals histogram
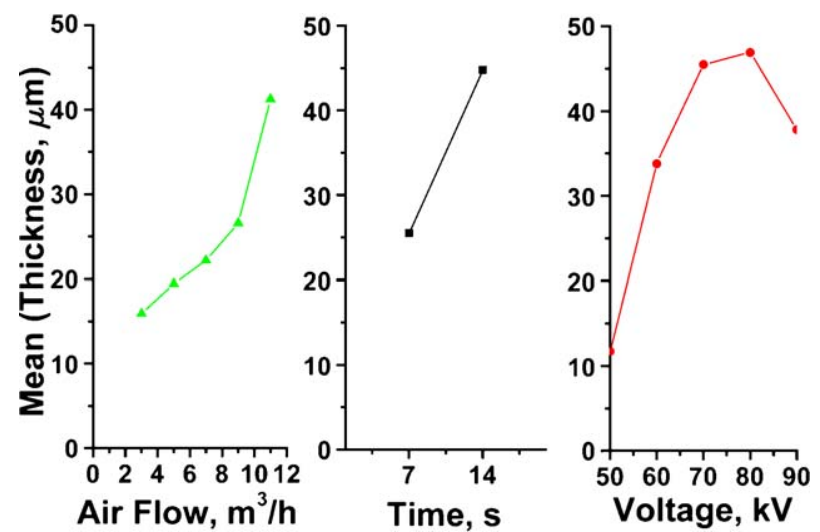

Fig. 10. Analysis of means for the full factorial experimental design.

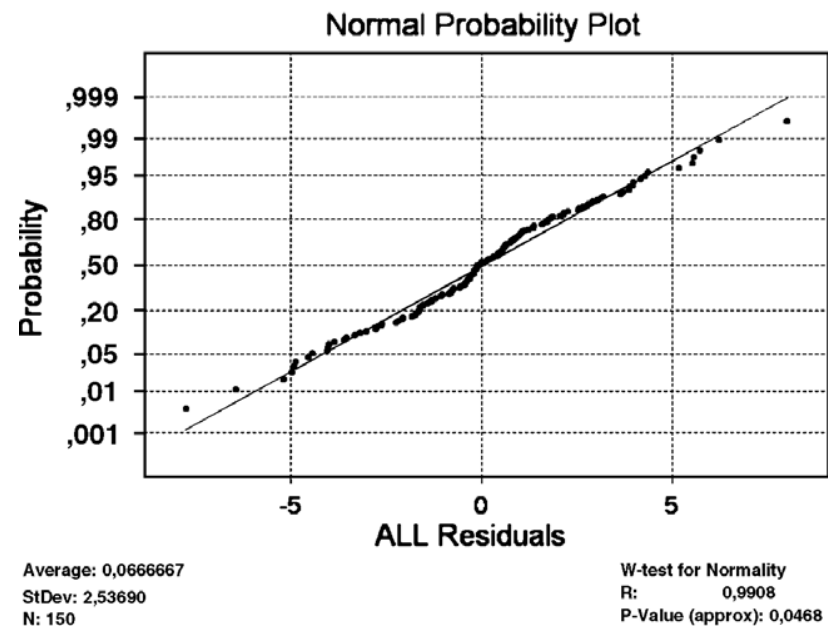

Fig. 11. Residuals analysis for the full factorial experimental design.

suggest sample data conform to a normal distribution. Residuals over time are randomly distributed because no bias or peculiar patterns occur. This confirms that the sequence of experiments does not influence the experimental data. Lastly, the chart of residuals shows that the relevant process does not run out of control.

\subsection{Verification experimental plan}

The analysis of results from full factorial design identified the most favorable operative condition relevant to industrial applications, that is to say, the quickest coating process with the best surface finishing and coating performance. The analysis above shows that an applied voltage set at $70 \mathrm{kV}$ seems to guarantee the best overall results. Further investigation of coating process at $70 \mathrm{kV}$ needs to vary both exposure time and applied voltage on several operative levels in order to verify previous hypothesis to a wider degree, and so the process capability.

Fig. 13 reports a coating thickness according to exposure time with flow rate, the applied voltage set being kept at 70 kV. Fig. 14 shows a 3D map for the coating thickness according to the exposure time and flow rate. A definite linear trend is achieved. This makes the coating process very easy to control due to the lack of electrical forces or effects negatively influencing deposition and so the development of the polymeric film and the overall performance of the coating.

In fact, for an admissible coating thickness as represented by one of the different colored map segments in Fig. 14, only one of the corresponding exposure time and flow rate value pairs needs to be chosen. The values of these pairs can be linearly increased or decreased if differences in workpieces geometry or in desired coating thickness arise.

Lastly, an analytical model was proposed on the basis of experimental results:

$s=A\left(t-t_{0}\right)^{p}$ 
Residual Model Diagnostics
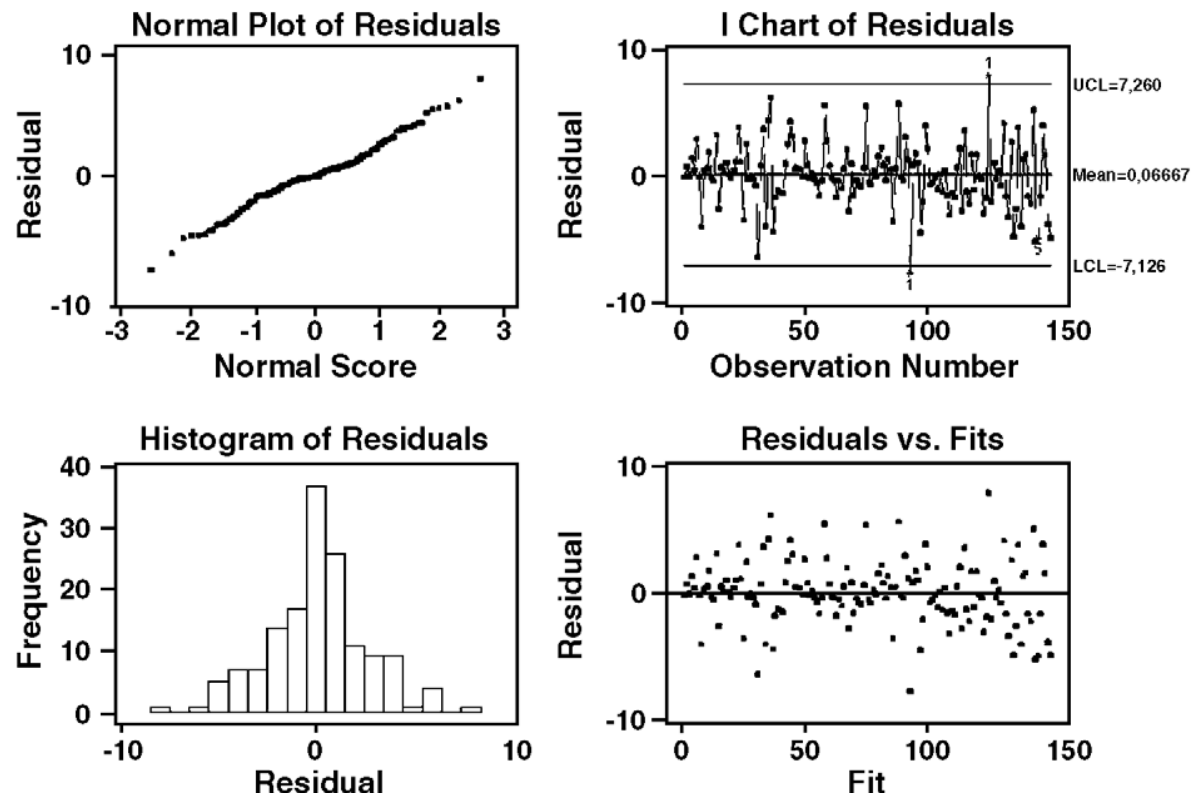

Fig. 12. Residuals model diagnostic for the full factorial experimental design.

where $s$ is the coating thickness, $t$ the exposure time, $t_{0}$ the starting time, and $A$ and $p$ are two empirical constants. Fig. 13 shows the multiple regression of the experimental data from which it can be seen that constant $p$ can be set at 0.75 for each curve achieved at different airflow. As a result, a hypothetical mono-parametric model which bonds thickness and exposure time can be formulated.

Parameter $A$ can be accurately calibrated. It is supposed to be a strict linear function of airflow, as Fig. 15 shows. In fact, when its value for each curve at different airflow is found, the resulting trend is linear. In the light of this, Eq. (1) can be re-written:

$s=\left(\kappa_{1}+\kappa_{2} F\right)\left(t-t_{0}\right)^{p}$

where $F$ is the airflow and $\kappa_{1}$ and $\kappa_{2}$ are two empirical constants which can be calibrated using the procedure

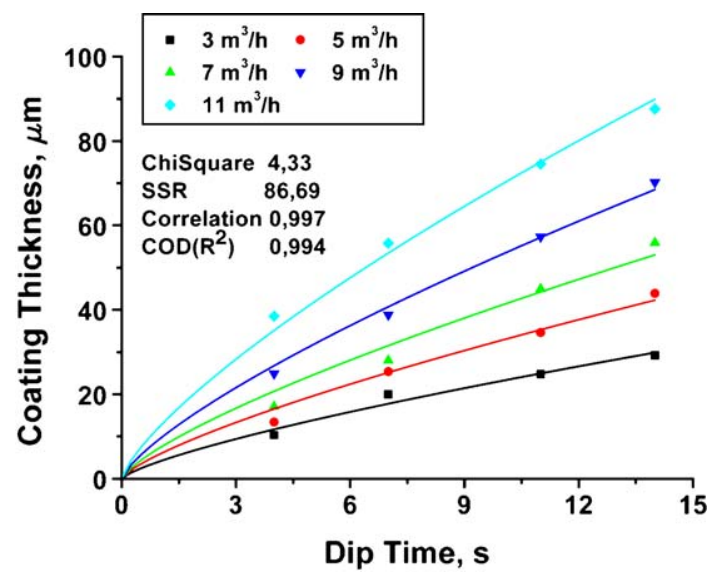

Fig. 13. Verification experiment: 2D map and analytical model. reported in Fig. $15\left(\kappa_{1}=-0.72\right.$ and $\left.\kappa_{2}=1.2\right)$. It is important to note that the calibration constant $A$ is worth 0 if airflow is set at $0.65 \mathrm{~m}^{3} / \mathrm{h}$, that is, the airflow corresponding to the minimum fluidization. Therefore, Eq. (2) can be rearranged as follows:

$s=\left(F_{s}-F_{m}\right)\left(t-t_{0}\right)^{p}$

where $F_{s}$ is the current airflow value and $F_{m}$ the minimum fluidization airflow.

Lastly, a normality test on residuals resulting from the procedure implemented in Fig. 15 determined an $R$ of approximately 0.95 and a $p$-value of more than 0.1 ,

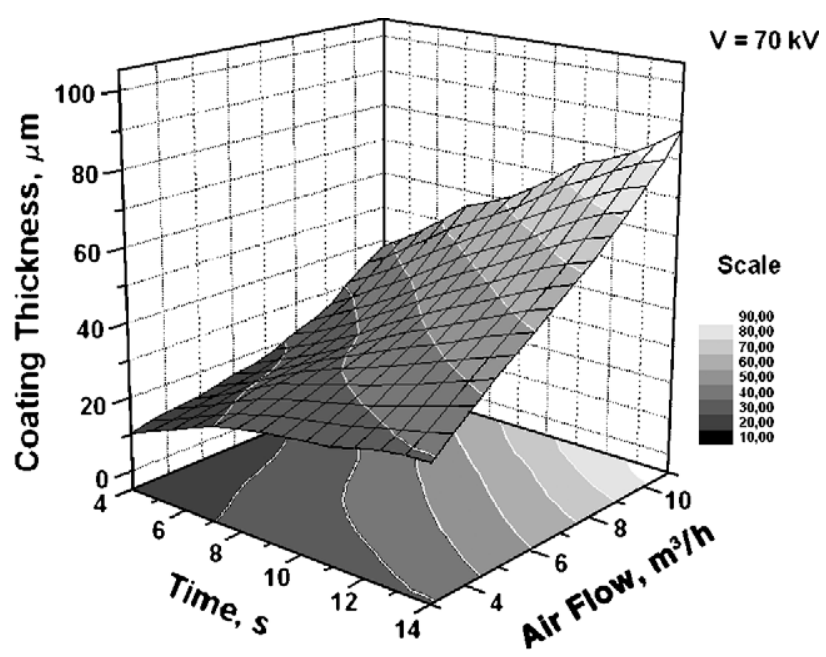

Fig. 14. Verification experiment: 3D map. 


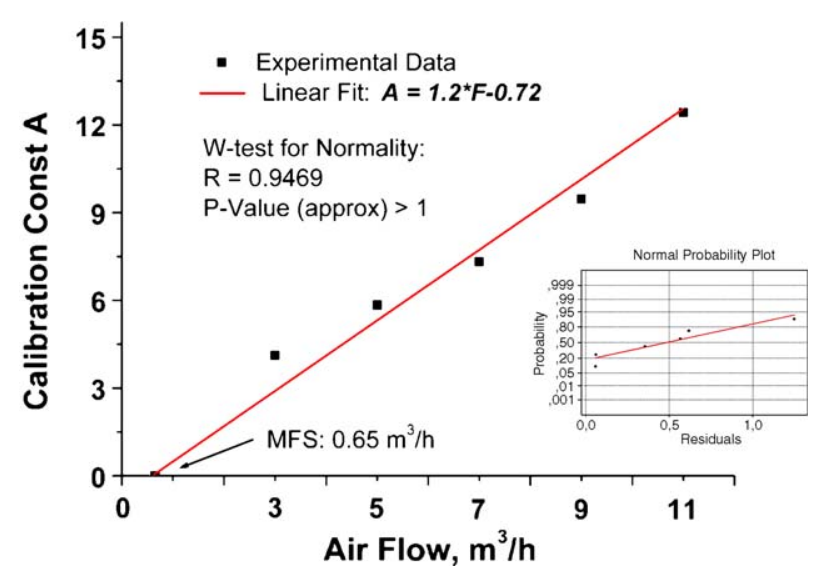

Fig. 15. Calibration constants.

confirming the accuracy of both the regression model and the calibration constants.

\section{Conclusions}

Detailed experimental investigation supported by a rigorous statistical analysis aimed at quantifying the influence of process parameters and fluidized bed hydrodynamic on electrostatic fluidized bed coating process on thin films (below $100 \mu \mathrm{m}$ ).

The relative influence of exposure time, airflow, and applied voltage on achievable coating thickness was measured. The statistical approach of the first Taguchi experimental design revealed the relevance of all the factors except for the powder typology. In addition, the slight impact of exposure time on coating thickness was found.

The experimental results of the next full factorial design showed the ability of fluidized bed to apply films under 100 $\mu \mathrm{m}$ thick and to manage the process accurately. Four process maps were drawn in which the influence of each process variable can be seen on coating thickness and average roughness. In particular, the voltage level $(70 \mathrm{kV})$ producing the highest coating thickness in the shortest possible time and without any deterioration in surface finish was discovered. The highest voltage levels resulted in electrical problems, that is to say, back ionization phenomena which produced a decrease in coating thickness and a related deterioration of surface aesthetic aspect (presence of voids, pin holes, craters, and 'orange peel' effect). The lowest voltage levels could cause weak powder adhesion or poor coverage on substrate and consequent deterioration of surface finishing.

A general linear model ANOVA and analysis of residuals was carried out to support the experimental results. Moreover, both analyses confirmed the indications presented by the experimental data and no significant error affected the experimental tests.

The results of the verification experimental plan revealed a definitively linear coating thickness trend, very promising in terms of process control, according to air flow and exposure time, once set the applied voltage at $70 \mathrm{kV}$. Moreover, achieved trends matched theoretic expectations very well.

Lastly, an analytical model was calibrated accurately by using an empirical constant related to the airflow and, then, validated by comparison with experimental trends. There was a good match between the model and experimental data. This demonstrates that the model predicts coating thickness trends, and forms the basis for the development of a process control system and a support for the powder coater in setting the operative parameters to obtain the best finishing of work-pieces.

\section{References}

[1] J.F. Richardson, in: J.F. Davidson, D. Harrison (Eds.), Fluidization, Academic Press, New York, 1971.

[2] G.S.P. Castle, J. Electrost. 51-52 (2001).

[3] M.R. Strucaly, Electrostatic Powder Coating for Armature Impregnation, Electrostatic Technology Inc., Branford, Connecticut (USA), 1977.

[4] M.R Strucaly, Electrostatic Technology, Inc. Bradford, Connecticut, USA, 1994.

[5] F.S. Ali, I.I. Inculet, IEEE Trans. Ind. Appl. 36 (5) (2000 September/ October).

[6] F.S. Ali, I.I. Inculet, IEEE Trans. Ind. Appl. 36 (5) (2000 September/ October).

[7] Q. Ye, T. Steigleder, A. Scheibe, J. Domnick, J. Electrost. 54 (2002) 189.

[8] Q. Ye*, J. Domnick, Powder Technol. 135-136 (2003) 250.

[9] ASME Metal Handbook, Paint and coating system, 1995.

[10] M. Barletta, G. Simone, V. Tagliaferri, Advance in Fluidized Bed Coating: An Experimental Investigation on a Performance Polymer Coating Alloy, 2004 (May) (submitted to Journal of material Processing and Technology).

[11] S. Guskov, Electrostatic Phenomena in Powder Coating, Powder System Group Nordson Corporation. 